\title{
Pelatihan Seni Membatik Bagi Masyarakat Desa Ngluwar, Kecamatan Ngluwar, Kabupaten Magelang
}

Djandjang Purwo Sedjati ${ }^{1}$, Yuni Estikasari ${ }^{2}$

${ }^{1}$ Program Studi Kriya, Fakultas Seni Rupa ${ }_{2}^{2}$ Jurusan Karawitan, Fakultas Seni Pertunjukan Institut Seni Indonesia Yogyakarta Jalan Parangtritis Km 6,5, Sewon, Bantul, Daerah Istimewa Yogyakarta 55188 No. Hp.: ${ }^{1}+62$ 812-2791-265, ${ }^{2}+6285726965547$ E-mail: 1mrs.djandjang@gmail.com, 2yuniestika18@gmail.com 


\title{
Pelatihan Seni Membatik Bagi Masyarakat Desa Ngluwar, Kecamatan Ngluwar, Kabupaten Magelang
}

\author{
Djandjang Purwo Sedjati ${ }^{1}$, Yuni Estikasari ${ }^{2}$ \\ ${ }^{1}$ Program Studi Kriya, Fakultas Seni Rupa \\ ${ }^{2}$ Jurusan Karawitan, Fakultas Seni Pertunjukan \\ Institut Seni Indonesia Yogyakarta \\ Jalan Parangtritis Km 6,5, Sewon, Bantul, Daerah Istimewa Yogyakarta 55188 \\ No. Hp.: ${ }^{1}+62812-2791-265,{ }^{2}+6285726965547$ \\ F-mail: 1'mrs.djandjang@gmail.com, 2yuniestika18@gmail.com
}

\begin{abstract}
Abstrak
Keterampilan seni membatik yang diberikan kepada anggota PKK Desa Ngluwar dari proses menggambar di atas kertas sampai melepaskan malam (nglorod), sebagai salah satu cara untuk mencapai tujuan pemberdayaan perempuan anggota PKK Desa Ngluwar, menambah keterampilan, meningkatkan sumber daya manusia, melestarikan batik, dan meningkatkan ekonomi masyarakat setempat. Metode pengabdian berupa ceramah, diskusi, praktik, dan evaluasi. Hasil yang dicapai dari penyuluhan seni batik ini adalah peserta dapat membuat batik sesuai prosedur pembuatan batik sehingga peserta yang belum pernah membatik menjadi bisa membatik. Peserta menghasilkan dua produk batik berupa sapu tangan ukuran 50 x $50 \mathrm{~cm}$ yang diproses dengan pewarna naptol dan kain panjang 2 meter yang diproses dengan pewarnaan remazol teknik colet dan celup.
\end{abstract}

Kata kunci: Desa Ngluwar, batik, pelatihan

\section{Batik Art Training to People in Ngluwar Village, Ngluwar Sub-District, Magelang Regency Abstract}

The batik art coaching taught to members of Ngluwar village PKK (group of housewives within close vicinity) covers from sketch drawing on paper to removing wax (nglorod). This is one of many methods to empower the locals to increase their skill, improving human resources, converse Batik heritage, and improve the local economy. The methods done are lecture, discussion, practice, and evaluation. The results from the batik art training shows that the participants are able to make batik craft according to procedure so that the people who have never made batik art before are now able to do it. Participants create two batik products which are handkerchief $50 \times 50 \mathrm{~cm}$ processed with Naptol fabric coloring and $2 \mathrm{~m}$ long fabric processed with Remazol through Colet technique (applying color directly using brush) and dip dye.

Keywords: Ngluwar Village, batik, training 


\section{PENDAHULUAN}

Desa Ngluwar merupakan salah satu wilayah desa yang terletak di Kecamatan Ngluwar, kabupaten Magelang, provinsi Jawa Tengah, yang memiliki 10 Dusun. Wilayah ini memiliki potensi yang cukup baik dalam bidang kesenian. Hal ini dapat dilihat adanya sebuah sanggar seni bernama Dua Atap yang menjadi wadah berkesenian. Sanggar Dua Atap pada tahun 2019 telah dibina dari Institut Seni Indonesia Yogyakarta dalam bidang seni pertunjukan. Sebagaimana Desa yang lain dalam struktur pemerintahan, Desa Ngluwar juga mempunyai wadah organisasi perempuan yaitu PKK Desa Ngluwar. Profesi anggota PKK diantaranya adalah ibu rumah tangga, pegawai negeri, usaha kuliner, dan lain sebagainya. PKK di wilayah ini pernah mendapatkan pelatihan membuat gantungan kunci dari benang dan pelatihan membuat kue.

Bangkitnya pariwisata di Indonesia termasuk Yogyakarta baik kunjungan wisatawan nusantara maupun mancanegara, membangkitkan pula batik Indonesia dari keterpurukan. Selain itu, bergairahnya kembali dunia batik Indonesia dipicu dengan dikukuhkannya batik Indonesia sebagai Masterpieces of the Oral and Intangible Heritage of Humanity atau sebagai warisan budaya Indonesia tak benda pada 2 Oktober 2009 oleh UNESCO, yang membawa konsekuensi bahwa batik harus tetap berkembang dalam kehidupan masyarakat Indonesia, sebab bila kehidupan batik tidak tumbuh dikehidupan masyarakat Indonesia, maka perdikat sebagai Masterpieces of the Oral and Intangible Heritage of Humanity akan dicabut kembali oleh UNESCO (2 Oktober 2009, UNESCO Akui Batik Sebagai Warisan Dunia Dari Indonesia, n.d.).

Sejalan dengan program pemerintah tentang ditetapkannya Batik sebagai warisan dunia tersebut, maka pemerintah Desa Ngluwar berupaya ikut berpartisipasi dalam rangka mengembangkan sumber daya perempuan di wilayahnya dengan keterampilan membatik. Selain itu, melihat situasi dan kondisi yang demikian, warga Desa Ngluwar yaitu dari anggota PKK Desa juga berkeinginan untuk bisa membatik seperti daerah lain yang sudah bisa membuat produk batik dan bahkan menjadi pekerjaan sambilan yang menambah penghasilan untuk menopang ekonomi keluarga.

Gayung bersambut, Institut Seni Indonesia Yogyakarta sebagai Perguruan Tinggi Seni melalui Lembaga Pengabdian Kepada Masyarakat juga mempunyai kepedulian untuk meningkatkan sumber daya manusia dengan memberikan keterampilan seni umumnya dan batik khususnya kepada masyarakat. Situasi dan kondisi yang demikian itu sangat mendukung diselenggarakannya pelatihan membatik dan Institut Seni Indonesia Yogyakarta berperan aktif serta bekerjasama dengan lembaga masyarakat dalam hal ini Pemerintah Desa Ngluwar untuk membina batik pada anggota PKK Desa menjadi sasaran penyuluhan.

Bangkitnya pariwisata di Indonesia termasuk kunjungan wisatawan domestik maupun mancanegara, membangkitkan pula batik Indonesia dari keterpurukan. Magelang sebagai wilayah yang memiliki banyak destinasi wisata diantaranya Candi Borobudur, Taman Kyai Langgeng, dan Museum Oei Hong Djien merupakan destinasi wisata yang banyak dikunjungi wisatawan domestik dan mancanegara. Hal ini dapat menjadi potensi pemasaran dari hasil kerajinan diantaranya batik. Telah diketahui bersama bahwa seni kerajinan batik merupakan pekerjaan yang banyak digeluti banyak masyarakat Indonesia dikarenakan dapat menjadi tumpuan ekonomi keluarga, sehingga bilamana batik ini banyak diminati oleh warga masyarakat Magelang tentunya akan menambah pendapatan keluarga dan mensejahterakan masyarakat Magelang khususnya di Desa Ngluwar. 
Situasi dan kondisi sebagaimana tersebut diatas sangat strategis dan membuka peluang bagi masyarakat setempat untuk ikut berpartisipasi dalam pelestarian batik agar dapat terus hidup dalam masyarakat termasuk masyarakat Desa Ngluwar. Bila dilihat dari lokasinya, wilayah Desa Ngluwar tidak begitu jauh dari Candi Borobudur, sehingga akan mudah bagi mereka untuk mempromosikan usahanya, karena akses yang mudah dijangkau. Mereka juga menyadari bahwa keterampilan membatik dapat dijadikan sebagai peluang usaha untuk mendapatkan tambahan penghasilan, bahkan dapat menjadi kegiatan untuk mencari nafkah.

Permasalahan yang dihadapi adalah mereka sama sekali belum mempunyai keterampilan dibidang batik dan belum pernah mendapatkan pelatihan atau pembinaan tentang batik. Dengan demikian untuk menambah dan meningkatkan sumber daya manusia dalam bidang batik sekaligus sebagai bentuk partisipasi penjagaan predikat Batik sebagai Pusaka dunia warisan tak benda dari UNESCO, maka diperlukan pelatihan membatik. Dalam rangka pemberdayaan perempuan maka sangat tepatlah kegiatan pelatihan batik ini diberikan kepada anggota PKK Desa Ngluwar. Harapannya adalah keterampilan atau keahlian yang diperoleh, nantinya dapat dijadikan sebagai modal dasar untuk membuka usaha baru yang dapat menjadi sarana untuk menambah penghasilan dan bahkan dapat menjadi kegiatan ekonomi untuk menunjang kebutuhan hidup keluarga serta menjadikan Desa Ngluwar sebagai wilayah yang ikut melestarikan keberadaan batik dan juga dapat menambah variasi potensi seni kerajinan di Desa Ngluwar, sekaligus dimungkinkan menjadi destinasi wisata setempat.

Tujuan melalui pengabdian kepada masyarakat ini, yaitu:
1. Memberdayakan perempuan khususnya anggota PKK Desa Ngluwar dengan menambah keterampilan dan meningkatkan sumber daya manusia tentang bagaimana membuat batik.

2. Ikut melestarikan keberadaan kehidupan batik di masyarakat dalam rangka ikut menjaga predikat batik Indonesia sebagai Masterpieces of the Oral and Intangible Heritage of Humanity dan memenuhi kebutuhan wisatawan, maka dapat menjadi kegiatan usaha untuk meningkatkan ekonomi masyarakat setempat.

Secara etimologi kata batik berasal dari bahasa Jawa "amba” yang berarti luas dan titik atau matik (kata kerja membuat titik) yang kemudian berkembang menjadi istilah "batik" yang berati menghubungkan titik-titik menjadi gambar tertentu pada kain yang luas atau lebar (Wulandari, 2011). Batik merupakan suatu hasil karya yang diperoleh dari proses menggambar pada media kain dengan lilin batik panas menggunakan bantuan canting atau alat cap yang terbuat dari tembaga ataupun kuningan. Teori ini digunakan dalam proses pelatihan membatik sebagai acuan langkah pembuatan batik dan teknik perwarnaannya.

\section{a. Kontribusi Hasil}

1. Bagi Masyarakat

Dapat meningkatkan pengetahuan serta menambah keterampilan tentang cara membuat batik tulis,yang kedepannya dapat kegiatan sampingan untuk menambah penghasilan, sehingga secara tidak langsung dapat meningkatkan taraf hidup masyarakat Desa Ngluwar, Kecamatan Ngluwar, Kabupaten Magelang.

2. Bagi Pemerintah

Bagi Pemda Magelang kegiatan ini telah seiring dengan program pemerintah Magelang, yaitu 
memberdayakan masyarakat tentang usaha keterampilan seni agar dapat berkembang sebagaimana dengan daerah lain yang telah berkembang lebih dahulu sehingga dapat menambah kesejahteraan bagi masyarakat di wilayahnya.

3. Bagi Perguruan Tinggi

Bagi Institut Seni Indonesia, penyuluhan seni ini sebagai bentuk pengabdian kepada masyarakat dibidang seni, agar masyarakat mengetahui bahwa Institut Seni Indonesia Yogyakarta peduli kepada masyarakat di sekitarnya, serta ikut berpartisipasi dalam rangka menjaga predikat Batik Indonesia sebagai Masterpieces of the Oral and Intangible Heritage of Humanity agar tidak dicabut lagi oleh UNESCO.

\section{METODE PENGABDIAN}

Metode pengabdian berupa penyuluhan melalui ceramah, diskusi, praktek dan evaluasi. Ceramah dan diskusi dalam memberikan materi penyuluhan pada pelaksanaannya meliputi:

1. Materi pengetahuan tentang batik secara umum.

2. Materi pengetahuan tentang alat dan bahan yang digunakan dalam membatik.

3. Materi membuat desain dan memindahkan ke kain.

4. Materi pengenalan penggunaan canting dan malam pada kain yang sudah sudah digambar.

5. Materi pewarnaan sintetis atau kimia naphtol dan remazol.

6. Materi cara menghilangkan atau melepaskan malam (nglorod).

Setelah pemberian materi melalui ceramah dan diskusi kepada peserta pelatihan yaitu anggota ibu-ibu PKK Desa Ngluwar, dilanjutkan dengan praktek langsung secara step by step. Mulai dari praktek membuat desain di atas kertas untuk sapu tangan ukuran 50 x 50 cm, memindah desain ke kain, praktek mencanting, pewarnaan napthol dengan teknik celup, dan nglorod. Tahapan praktek dimulai dari produk yang berukuran kecil seperti sapu tangan karena, peserta masih dalam tahap belajar dan belum pernah membuat batik. Setelah praktek pada kain kecil, kemudian beralih pada kain dengan ukuran 2 meter sebagai bahan sandang. Evaluasi dilakukan di akhir kegiatan praktek untuk mengetahui kendala dan solusi untuk keberlanjutan kegiatan membatik yang lebih baik.

\section{HASIL DAN PEMBAHASAN}

Sasaran kegiatan pelatihan seni membatik adalah anggota PKK Desa Ngluwar, Kecamatan Ngluwar, Kabupaten Magelang, Provinsi Jawa Tengah. Tempat kegiatan penyuluhan dilakukan di rumah ketua PKK Desa Ngluwar yang beralamat di Dusun Babadan, Desa Ngluwar dengan 20 peserta. Kegiatan penyuluhan pelatihan seni membatik dilakukan mulai tanggal 10 Maret samapai 30 Agustus dengan total pertemuan 12 kali. Hasil yang dicapai dari penyuluhan seni batik ini adalah peserta pelatihan ibu-ibu PKK Desa Ngluwar dapat mengerjakan atau membuat batik selangkah demi selangkah sesuai dengan prosedur dalam proses pembatikan, sehingga peserta yang belum pernah membatik menjadi bisa membatik. Pada pelatihan ini, masingmasing peserta dapat membuat 2 produk batik yaitu sapu tangan 50 x $50 \mathrm{~cm}$ yang diproses dengan pewarna naphtol dan kain batik untuk busana dengan ukuran panjang 2 meter, yang diproses dengan pewarnaan remazol colet dan celup.

Gambar 1 menunjukan peserta pelatihan sedang praktek menggambar desain di atas kertas berupa motif-motif sederhana seperti motif parang. Gambar 2 menunjukan proses 
pencantingan pada kain menggunakan lilin panas dan canting. Praktek pewarnaan menggunakan zat warna napthol dengan teknik celup dapat dilihat pada gambar 3, peserta pelatihan antusias dan berkerumun melihat langsung langkah pewarnaan batik. Dengan dibuatnya dua produk berupa sapu tangan dan kain untuk bahan sandang, peserta menjadi lebih paham tentang proses membatik dan hasilnya dapat dilihat pada gambar 4. Gambar 5 menujukan peserta pelatihan dalam hal ini adalah anggota PKK Desa Ngluwar telah sepakat membentuk kelompok usaha batik dengan nama Canthing Kuning. Tentu saja keberadaan kelompok ini dapat menambah jumlah kelompok usaha seni kerajinan batik di Magelang.

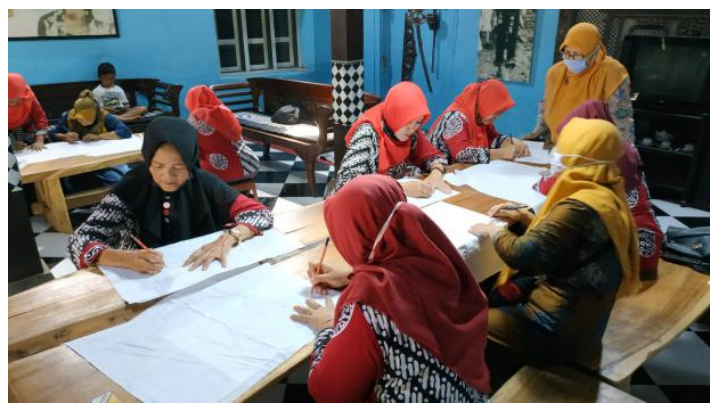

Gambar 1. Belajar menggambar motif parang (Foto Djandjang Purwo Sedjati, Maret 2020)

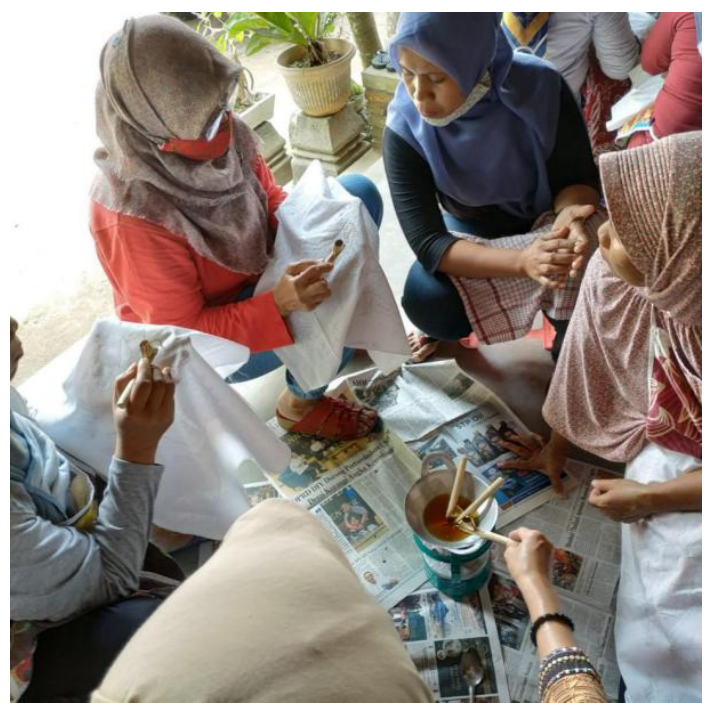

Gambar 2. Praktek mencanting di atas kain (Foto Djandjang Purwo Sedjati, Maret 2020) 


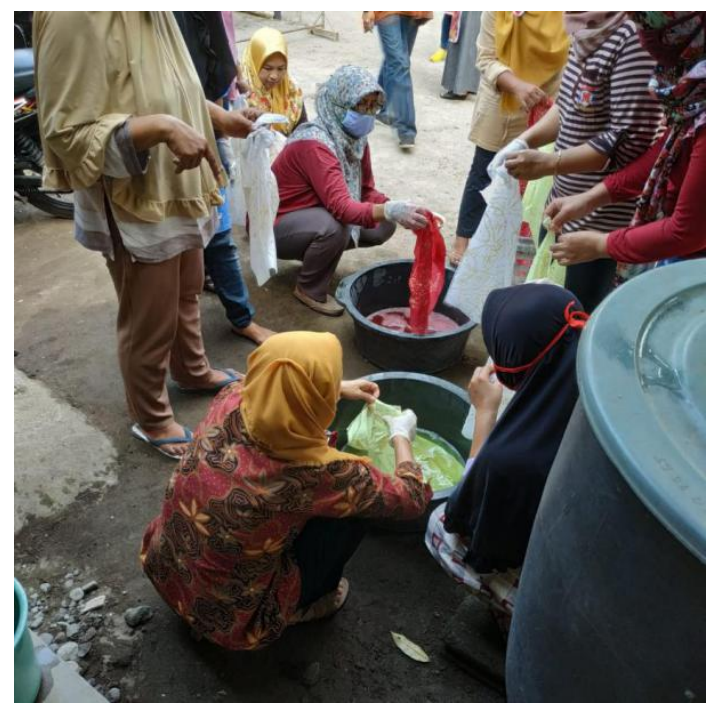

Gambar 3. Pewarnaan dengan napthol teknik celup (Foto Djandjang Purwo Sedjati, April 2020)

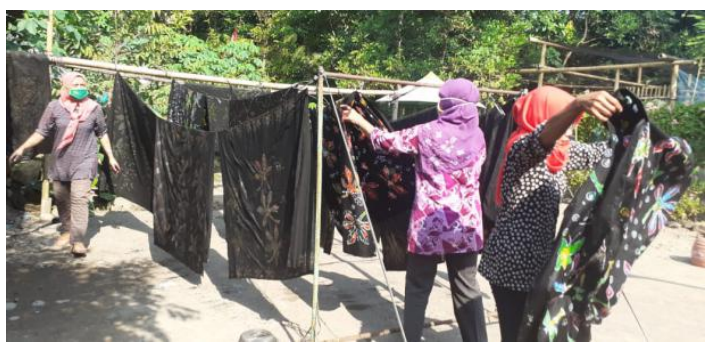

Gambar 4. Hasil Karya (Foto Djandjang Purwo Sedjati, Agustus 2020)

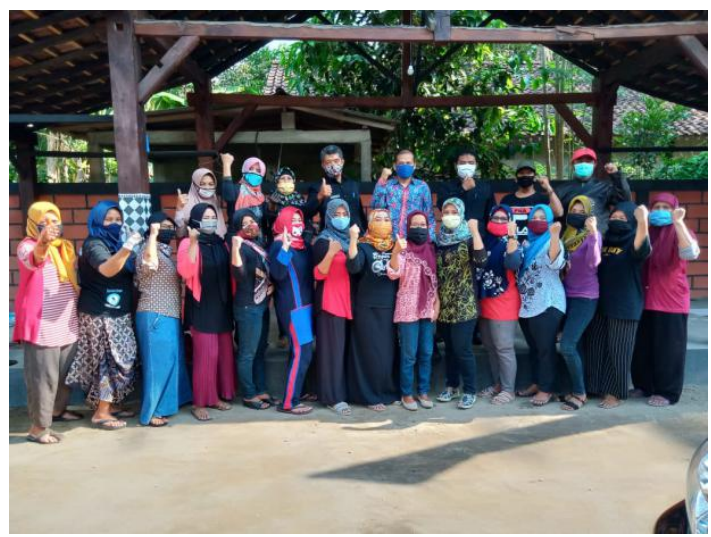

Gambar 5. Pembentukan kelompok usaha batik Canthing Kuning (Foto Djandjang Purwo Sedjati, Agustus 2020)

\section{KESIMPULAN}

Peserta pelatihan batik dari anggota PKK

Desa Ngluwar, Kecamatan Ngluwar, Kabupaten Magelang sangat antusias dalam mengikuti pelaksanaan penyuluhan seni ini. Hasilnya cukup baik bagi para pembatik pemula. Ada beberapa dari peserta yang kemampuan mencantingnya sudah baik, namun yang lain masih perlu banyak berlatih agar kemampuan mencantingnya lebih baik. Dari hasil pelatihan, peserta bisa membuat batik dengan pewarna naphtol dan pewarna remazol dengan teknik colet dan tutup celup dengan baik meskipun belum sempurna. Pada 
pelatihan ini ada dua produk yang dibuat yaitu saputangan ukuran 50 x 50cm dengan pewarna naphtol dan bahan sandang 2 meter yang diproses dengan pewarnaan remazol colet dan celup.

\section{SARAN}

Telah diketahui bersama bahwa kegiatan membuat batik dapat menjadi lapangan kerja yang dapat diandalkan. Oleh karena itu kegiatan ini dalam rangka pemberdayaan perempuan sebaiknya dilaksanakan berkelanjutan, sehingga diharapkan anggota PKK ini nantinya akan mendapatkan pelatihan yang berkaitan dengan batik tulis lagi, khususnya dalam hal pengembangan desain dan pendalaman materi. Hal tersebut dikarenakan dalam pelatihan ini masih dalam taraf batik bagi pemula sehingga belum menyentuh tentang materi desain lebih dalam. Peserta belum menciptakan sendiri desain-desain yang diterapkan, melainkan masih menggunakan desain yang telah disiapkan pembina.

\section{UCAPAN TERIMA KASIH}

Terimakasih kepada pihak yang membantu serta mendukung pelatihan seni membatik bagi masyarakat Desa Ngluwar melalui kegiatan Penyuluhan Seni, diantaranya:

1. Dr. Nur Sahid, M.Hum., selaku ketua LPPM Institut Seni Indonesia Yogyakarta.

2. Bapak Sunandar, selaku kepala Desa Ngluwar.

3. Ibu Yayuk, selalu ketua dari PKK Desa Ngluwar yang telah bersedia menyediakan tempat pelatihan.

\section{DAFTAR PUSTAKA}

2 Oktober 2009, UNESCO Akui Batik sebagai Warisan Dunia dari Indonesia. (n.d.). Retrieved May 15, 2021, from https: / / nasional.kompas.com/read/20 17/10/02/08144021/2-oktober-2009unesco-akui-batik-sebagai-warisandunia-dari-indonesia

Wulandari, A. (2011). Batik Nusantara: Makna Filosofis, Cara Pembuatan dan Industri Batik. Yogyakarta: Andi Offset. 